\title{
Macrophage heterogeneity in normal colonic mucosa and in inflammatory bowel disease
}

\author{
M C Allison, S CORNWAll, L W POUlter, A P DHillon, \\ AND R E POUNDER \\ From the Academic Departments of Medicine, Immunology and Histopathology, Royal Free Hospital School \\ of Medicine, London
}

\begin{abstract}
SUMMARY Immunohistological techniques using monoclonal antibodies were employed to study the morphology and phenotypic expression of macrophage like cells in ulcerative colitis, Crohn's colitis and histologically normal colonic mucosa. The antibody RFD1 identifies interdigitating (antigen presenting) cells whereas RFD7 binds to mature tissue macrophages. In normal colonic mucosa, the majority of cells recognised by these reagents were positive for Class II antigen expression and a median 87\% (range 80-95\%) were positive for both RFD1 and RFD7, with 6.5\% (ranges 1-14\%) positive for either antibody alone. There was much greater macrophage heterogeneity in the ulcerative colitis and Crohn's colitis biopsies than in normal mucosa. Clusters of RFD9+ cells (epithelioid cells) were found in Crohn's colitis and, to a lesser extent, in ulcerative colitis. Some Crohn's colitis sections showed replacement of the normal colonic macrophage phenotype with RFD1-RFD7+ cells (classical scavenger macrophages). The degree of this replacement correlated with the histological severity of the disease. By contrast, large numbers of RFD1+ RFD7- cells, with long dendritic processes, were found in intimate association with the lymphoid infiltrates in the lamina propria of the ulcerative colitis sections. Future studies of the factors controlling macrophage differentiation in tissues may help to explain the greater macrophage heterogeneity in inflammatory bowel disease and the differences between ulcerative colitis and Crohn's colitis observed in this study.
\end{abstract}

It is probable that non-lymphoid mononuclear cells (macrophage like cells) play an important role in the chronic intestinal inflammation that characterises ulcerative colitis (UC) and Crohn's disease. The absolute peripheral blood monocyte count is increased in these diseases and correlates with disease activity. ${ }^{1}$ There is an increased density of mucosal macrophages in Crohn's disease compared with control samples, ${ }^{2}$ however, studies of macrophage turnover showed only a slight increase in patients with UC and Crohn's disease. ${ }^{3}$

The advents of monoclonal antibodies and intestinal mucosal cell isolation techniques have stimulated much interest in possible disorders of

Address for correspondence: Dr M C Allison, Gartnavel General Hospital, Great Western Road, Glasgow G12 OYN.

Received for publication 1 June 1988. mucosal immune regulation in inflammatory bowel disease, but the tissue subpopulations of macrophage like cells and their possible functional interrelationships has received little attention. Selby et al reported that large numbers of irregular histiocytes expressing Class II antigens and strong cytoplasmic acid phosphatase activity, were present in colonic mucosa from patients with active inflammatory bowel disease, but absent from normal mucosa. ${ }^{4}$ Time lapse photography of intestinal mononuclear cell preparations from patients with inflammatory bowel disease has revealed significant numbers of veiled cells, a finding not present in control preparations. ${ }^{5}$ The veiled cell is a type of dendritic cell capable of presenting antigen to immunocompetent T lymphocytes. ${ }^{6}$

It is now recognised that the macrophage family of cells is heterogeneous. The dendritic cell is con- 
sidered to be a specialised antigen presenting cell that is morphologically and functionally distinct from the classic phagocytic tissue macrophage.? The epithelioid cell is another member of the macrophage family that is poorly phagocytic and is seen characteristically in association with granulomas. ${ }^{8}$ Monoclonal antibodies capable of distinguishing subpopulations of macrophage like cells have been developed recently. ${ }^{90}$ Immunohistological studies using these reagents may help to unravel the pathogenetic mechanisms underlying chronic inflammatory disorders. We have applied this technology to the study of histologically normal colonic mucosal sections, comparing the results with samples from patients with active UC or Crohn's disease.

\section{Methods}

\section{PATIENTS}

Histologically normal colonic biopsies or resection specimens were obtained from nine patients without inflammatory bowel disease. Five patients had undergone segmental colectomy for colorectal carcinoma, and samples were taken at least $10 \mathrm{~cm}$ away from the tumour in these cases. Four histologically normal colonic biopsies were obtained from patients undergoing colonoscopy for investigation of large bowel symptoms; a clinical diagnosis of irritable colon had been made in these patients. Mucosal biopsies or resection specimens were also obtained from areas of endoscopic and histological involvement with UC (five patients) and Crohn's colitis (12 patients). The diagnosis of ulcerative colitis and Crohn's colitis had been independently established by endoscopic, radiological, and histological criteria in each case.

PREPARATION OF TISSUES

Tissue samples were orientated on cork, covered with OCT compound (Miles Scientific Laboratories Ltd) and snap-frozen in isopentane in a liquid nitrogen bath. Cryostat sections $6 \mu \mathrm{m}$ thick were cut

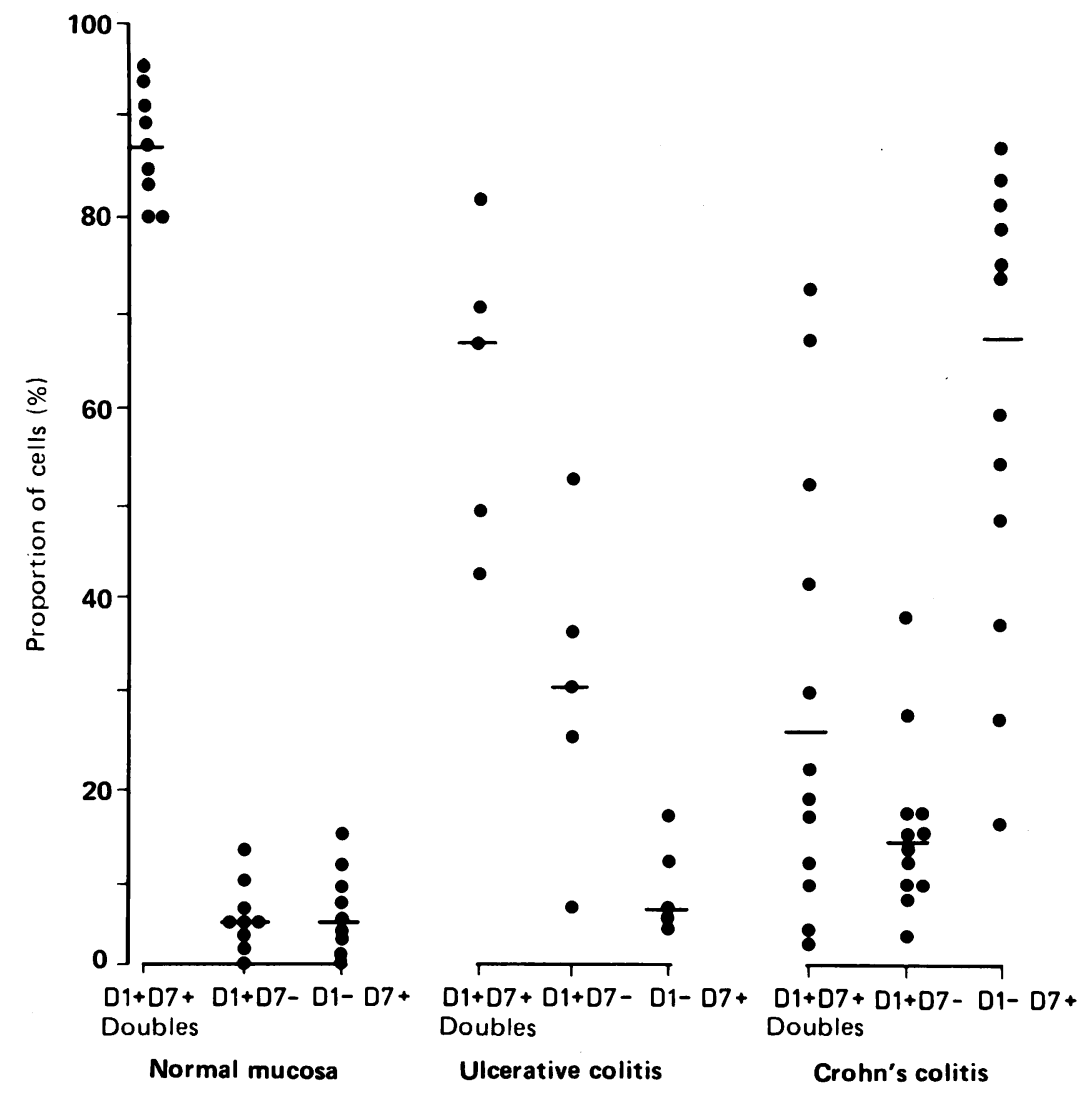

Fig. 1 Results of double immunofluorescent labelling of macrophage like cells in normal colonic mucosa $(n=9)$, ulcerative colitis $(n=5)$, and Crohn's colitis $(n=12)$. Results are expressed as proportions of cells labelled by both RFD1 and RFD7 (doubles), RFD1 alone, and RFD7 alone. 
at $-35^{\circ} \mathrm{C}$, air dried, and fixed for 10 minutes in a $1: 1$ solution of chloroform and acetone.

HISTOLOGICAL EXAMINATIONS

Serial sections from the snap frozen tissue block were examined histologically and immunohistologically by independent observers. Histological examination was done by light microscopy after routine haematoxylin and eosin staining. Samples from the 12 patients with Crohn's disease were ranked by the histopathologist (APD) in order of increasing severity $(1=$ least inflamed, $12=$ most inflamed $)$.

MONOCLONAL ANTIBODIES

The antibodies used in this study were RFDR1 (identifying an HLA-DR framework epitope), RFD1 (interdigitating cells), RFD7 (mature macrophages), RFD9 (epithelioid cells and tingible body macrophages), and UCHM1 (monocytes). The preparation and reactivity of these antibodies have been described elsewhere. ${ }^{9-12}$ Peripheral blood monocytes are positive for UCHM1, but negative for the other markers used in this study.

\section{IMMUNOPEROXIDASE STUDIES}

An indirect immunoperoxidase method was used. ${ }^{13}$ Tissue sections were incubated with the monoclonal antibodies in parallel with positive control sections (human palatine tonsil) for one hour. One section from each patient was incubated in phosphate buffered saline (PBS) alone and served as a negative control. After rinsing in PBS for five minutes, all sections were incubated in a rabbit antimouse peroxidase conjugate for 45 minutes. Further rinsing was followed by development with a solution containing hydrogen peroxide and di-amino benzidine. Preparations were counterstained in Harris' haematoxylin, dehydrated, and mounted in DPX (BDH Chemicals Ltd). Each section was analysed using a computer assisted morphometry device (Medical Research Council, SSRCON Software package). This equipment enables the observer to draw a two dimensional map of the mucosal field being studied under the microscope. Areas occupied by lymphoid follicles, luminal and glandular epithelium can be subtracted from the total area of the field to give the area occupied by the lamina propria. Any cells within that area exhibiting identifiable reactions on their cell membranes distinct from background were scored as positive. The number of positive cells per $\mathrm{mm}^{2}$ of lamina propria was calculated from the printout.

DOUBLE IMMUNOFLUORESCENT STUDIES Double immunofluorescence labelling was done using a combination of RFD1 (IgM class) and RFD7 (IgG class) as a first layer. ${ }^{14}$ After washing in PBS, the sections were incubated with a second layer mixture of anti-IgG FITC (fluorescein isothiocyanate) and anti-IgM TRITC (tetraethyl rhodamine isothiocyanate) in PBS. Preparations were mounted in buffered glycerol and viewed with a Zeiss microscope equipped with epifluorescent illumination and selective filters for FITC and TRITC. At least 150 mucosal macrophage like cells in each section were assessed for the presence or absence of one or both markers. The validity of this method of quantification was examined by assessing the presence of each marker (or both) on 150-200 cells in 10 different fields of one large section of normal mucosa and calculating the percentage standard errór of count variability between these 10 fields.

\section{STATISTICAL ANALYSIS}

Significances of observed differences between the groups in absolute numbers of RFD1+ and RFD7+ cells per $\mathrm{mm}^{2}$, and in percentage proportions of cells bearing one or both markers, were assessed using unpaired Wilcoxon's tests. The Crohn's colitis sections were examined for the degree of correlation between the histological disease severity ranking and the proportion of cells positive for RFD7 alone.

\section{Results}

VALIDATION OF DOUBLE IMMUNOFLUORESCENT COUNTS

The standard errors for counts of cells positive for each marker in $\mathbf{1 0}$ different fields of a histologically normal section were $2 \cdot 12 \%$ for RFD1+ RFD7+, $1.96 \%$ for RFD1+ RFD7 - cells and $1.14 \%$ for RFD1- RFD7+ cells. These low percentage standard errors suggest that individual counts of 150200 fluorescing mucosal macrophage like cells are reasonably representative of the section as a whole and that sampling differences are not a major problem in the interpretation of histologically normal mucosa. The same assumption cannot be made in UC or Crohn's colitis because the inflammatory changes may be patchy.

NORMAL COLONIC MUCOSA

Epithelial cells were negative for RFDR1 in all samples of normal colonic mucosa, a finding in agreement with previous observations using other markers for Class II antigen expression. ${ }^{15}$ The distributions and phenotypic expression of macrophage like cells within the lamina propria were very similar in all the samples of normal colonic mucosa that were studied. RFDR1 and RFD1 labelled many large nonlymphoid cells between the crypts and immediately beneath the epithelial surface. Lymphoid cells scattered within the lamina propria were negative for 

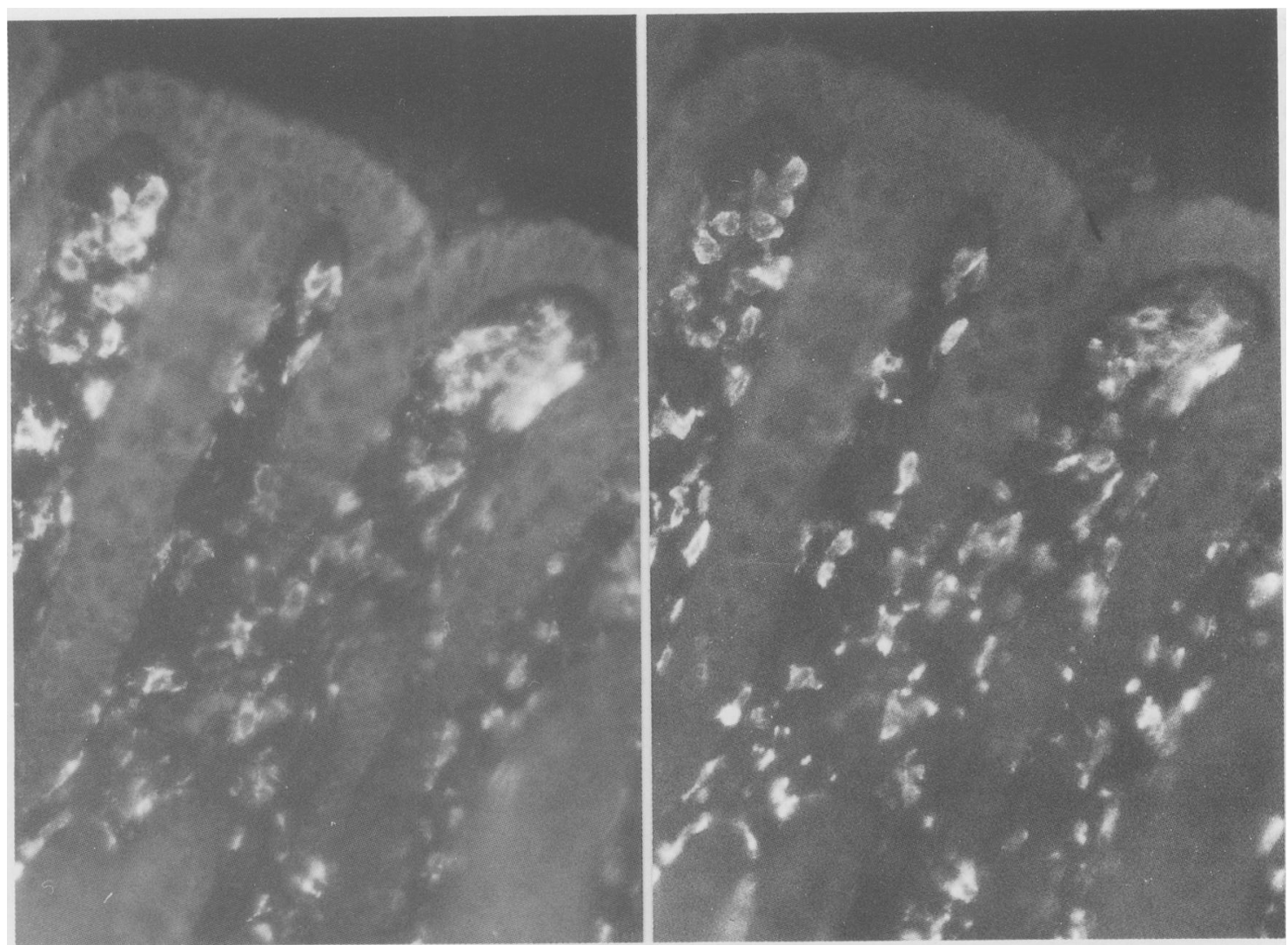

Figs 2a, b Double RFDI/RFD7 immunofluorescence preparation of a section of histologically normal colonic mucosa. When viewed with red fluorescent light $(a)$, numerous $R F D 1+$ non-lymphoid cells are seen distributed throughout the lamina propria, especially just beneath the epithelial surface. Using green fluorescence (b), numerous RFD7+cells become apparent. Most cells identified by these markers are clearly positive for both.

RFDR1 and RFD1, but there were some RFD1+ round cells within the lymphoid aggregates (RFD1 binds to about $20 \%$ of tonsillar B cells). ${ }^{4}$ RFD7 identified many non-lymphoid stellate and fusiform cells distributed throughout the lamina propria. Morphometry showed approximately equal numbers of RFD1+ cells (median $265 / \mathrm{mm}^{2}$ lamina propria) and RFD7+ cells (mean $245 / \mathrm{mm}^{2}$ ). Double immunofluorescence showed that approximately $87 \%$ of cells fluorescing with RFD1 or RFD7 were positive for both reagents (doubles) and that equally small numbers of cells were positive for either reagent alone (Figs 1, 2a, and b). RFD9+ cells were confined to lymphoid aggregates. A few UCHM1+ cells were seen between the crypts.

ULCERATIVE: COIITIS

The epithelium in these sections was RFDR1+, in keeping with previous observations. ${ }^{\text {s }}$ The inflamed lamina propria contained similar numbers of RFD1+ and RFD7+ cells (medians $299 / \mathrm{mm}^{2}$ and $206 / \mathrm{mm}^{2}$ respectively) when compared with the histologically normal mucosa. Aggregates of RFD7+ and RFD9+ cells were seen in the basal quarter of the lamina propria. A typical basal aggregate of RFD9+ cells is shown in Figure 3. Double immunofluorescence revealed that RFD1+ RFD7+ doubles were significantly less common in UC than in normal mucosa (medians 66\% v 87\%, p $<0.01$ ) and that RFD1+ RFD7 - cells were much more frequent in UC $(30 \%$ $v 6 \%, \mathrm{p}<0.01)$. Interestingly the RFD1+ 'singles' in UC exhibited long thin processes up to $50 \mu \mathrm{m}$ long that formed a branching network within the lamina propria (Fig. 4).

CROHN'S COLITIS

The epithelium in the 10 most inflamed sections was RFDR1+, as in UC. As might be expected in this 


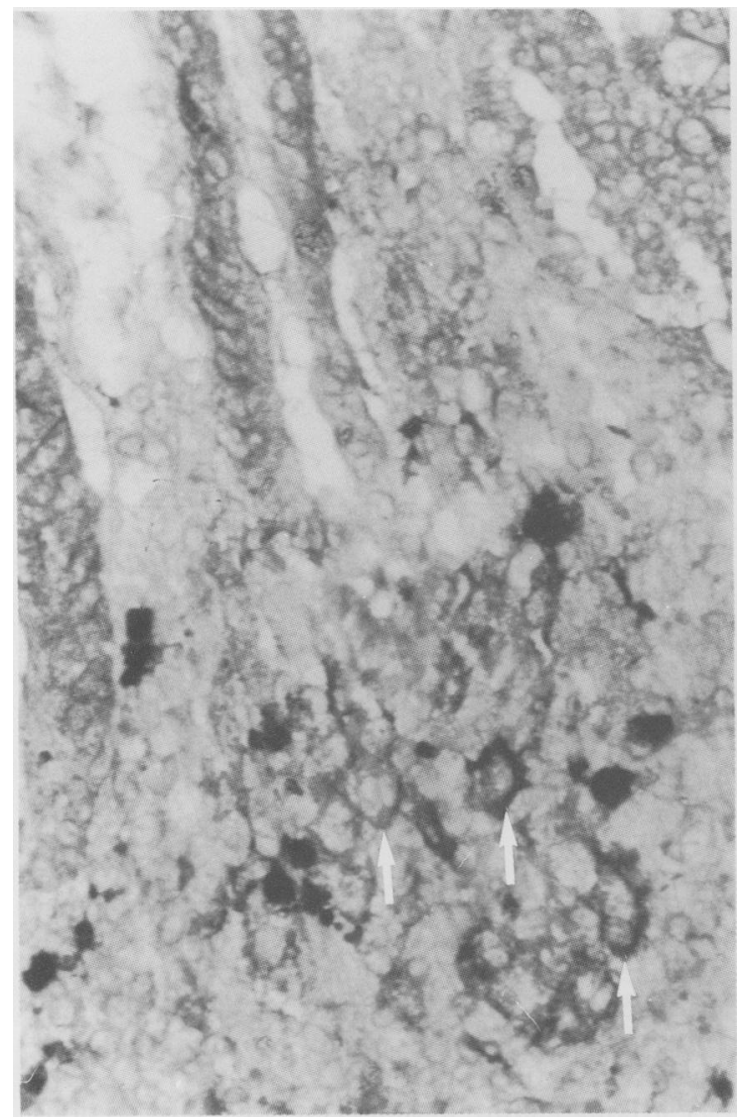

Fig. 3 Immunoperoxidase preparation of a section of colonic mucosa from a patient with active ulcerative colitis. The monoclonal antibody RFD9 has identified several large macrophage like cells with darkly staining membranes (arrows). This collection of epithelioid cells is situated at the base of a disrupted crypt.

disease there were striking abnormalities in the mucosal macrophage patterns. The most obvious difference from normal and UC was the smaller number of RFD1+ cells per unit area of lamina propria (medians $41 v 265 / \mathrm{mm}^{2}$ in normal subjects, $\mathrm{p}<0.05)$ and in the proportions of RFD1+ RFD7+ doubles (Figs 1 and 5). This apparent loss of RFD1+ cells was particularly obvious in the most inflamed sections especially adjacent to mucosal aphthoid ulcerations, fissures or granulomas. Double immunofluorescence showed a concomitant rise in the proportion of RFD7+ 'singles' $(65 \%, 7 \%$ in normal subjects, $p<0 \cdot(01)$. The falls in proportions of RFD1 + RFD7+ doubles and the rises in proportion of RFD7+ 'singles' correlated with histological disease severity $(\mathrm{r}=-0.62$ and +0.62 , respectively: $\mathrm{p}<0.05) \quad$ (Fig. 6). Immunoperoxidase staining

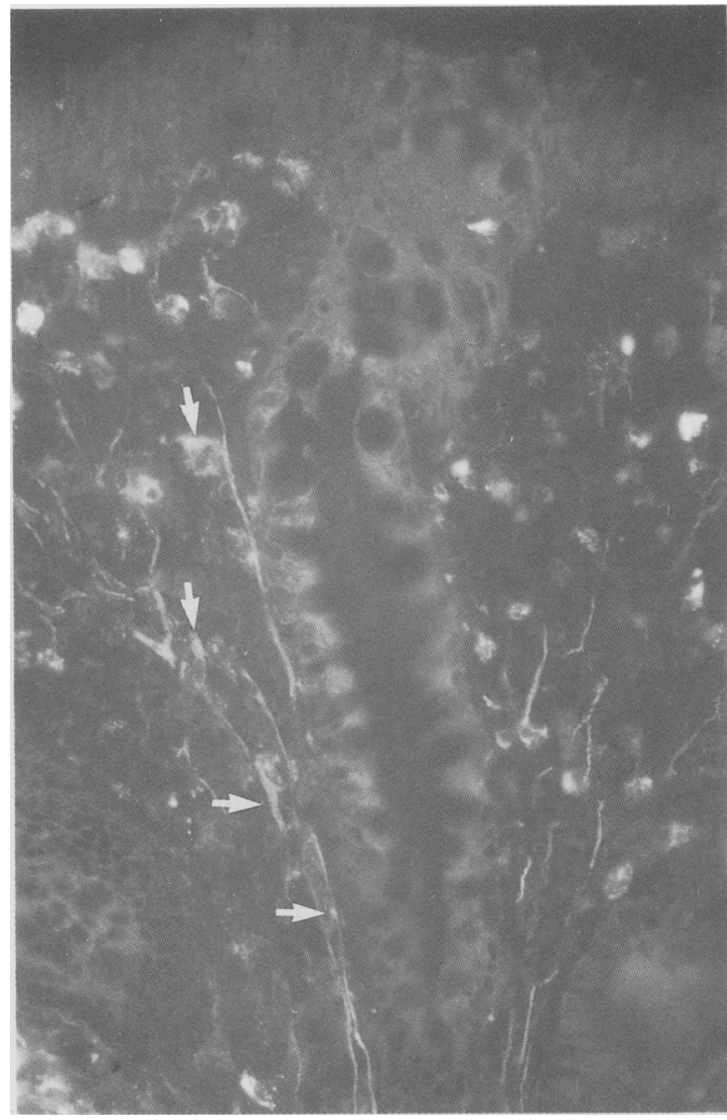

Fig. 4 RFDI immunofluorescence preparation of a section from a patient with active ulcerative colitis. There are many irregular RFDI+ cells with long processes in the lamina propria of this section (arrows).

revealed populations of UCHM1 + cells within the infiltrates of RFD7+ cells. Focal accumulations of RFD7+ and RFD9+ cells were abundant in the areas of greatest histological abnormality within the lamina propria, extending deep into the submucosa in many cases. The surviving RFD1+ cells extended long processes similar (but less impressive) in appearance to those in UC.

\section{Discussion}

The majority of macrophage like cells in normal colon were found to be positive for RFDR1, RFD1, and RFD7 but negative for UCHM1. Most of these large stellate cells have the morphology of interdigitating cells and lie immediately beneath the columnar epithelial layer. These findings are of great interest because cells bearing the RFD1+ RFD7+ phenotype have not been found in any other histo- 


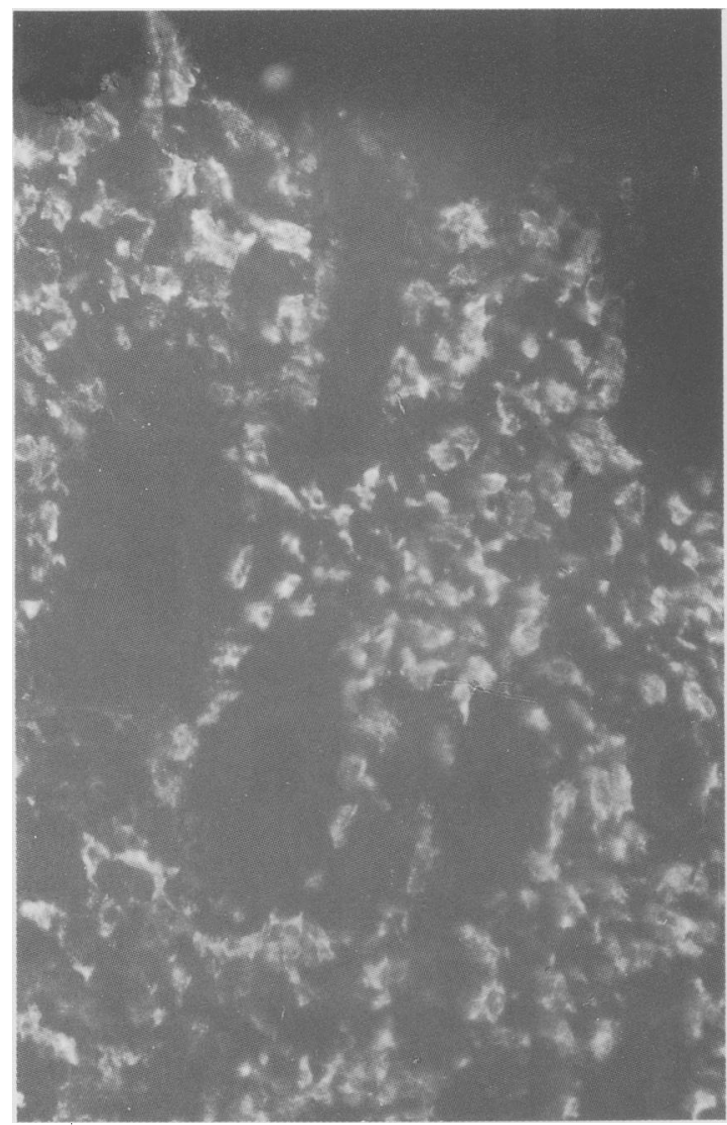

Fig. 5 RFD7 immunofluorescence preparation of a section from a patient with severe Crohn's colitis. There is a dense accumulation of RFD7+ cells, nearly all of which are RFDI-.

logically normal tissue so far studied. A few RFD1+ RFD7+ cells are present in bronchoalveolar lavage fluid from normal subjects but this cell phenotype is not seen in histologically normal transbronchial biopsies. ${ }^{16}$ Large numbers of RFD1+ RFD7+ cells have been found in sections of pannus synovial lining from patients with rheumatoid arthritis ${ }^{17}$ and in the lesions of lepromatous leprosy. ${ }^{18}$

There was a wide spectrum of morphological appearances and phenotypic expressions of macrophage like cells in UC and Crohn's colitis. This heterogeneity was much greater than in normal colon and was particularly obvious in the sections where histological severity was judged to be greatest. The findings confirm and extend those of Selby and his colleagues. ${ }^{4}$ Their histochemical study of HLA-DRpositive histiocytes (those expressing Class II antigens) suggested that at least two different subpopulations were present in normal colonic mucosa

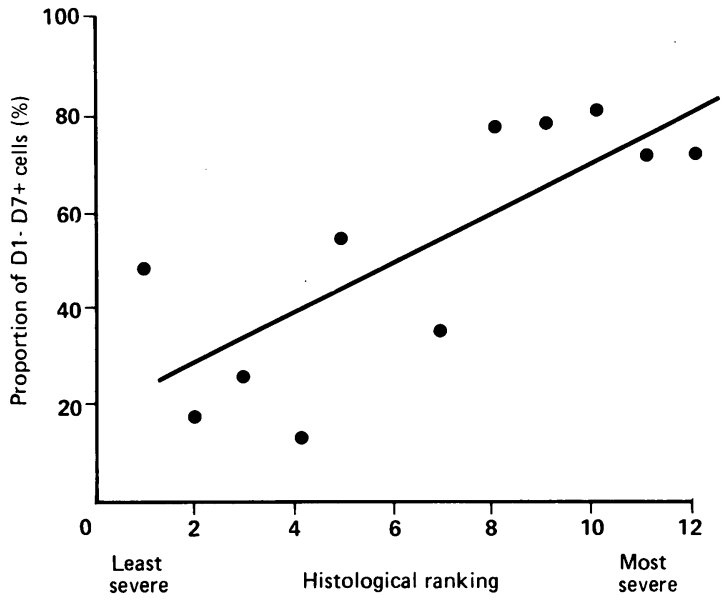

Fig. 6 The proportions of cells, recognised by the markers RFDI and RFD7, that were positive for RFD7 alone (RFD7+ singles) in each Crohn's colitis section has been plotted against the independently assessed histological severity ranking of that section. There is a positive correlation between the proportion of RFD7+ singles and histological severity $(r=0.62, p<0.05)$.

and that a third population emerged in inflammatory bowel disease. The present study provides further evidence for the hypothesis that greater macrophage heterogeneity in inflammatory bowel disease may represent a state of mucosal activation in response to an invading antigen.

A striking feature in the ulcerative colitis sections was the identification of RFDR1+ RFD1+ RFD7cells with long dendritic processes in areas of extensive lymphoid infiltration. These cells were less obvious in Crohn's colitis and absent from normal mucosa; they may be the same population as the veiled cells observed by Wilders et al..$^{5}$ Their morphology, distribution and expression of RFD1 and Class II antigen are all consistent with the belief that these cells are actively presenting antigen to helper T lymphocytes which would, in itself, initiate or perpetuate a cell-mediated immune response. An identical cell phenotype prevails in the extensive lymphoid infiltrates of rheumatoid synovium, ${ }^{17}$ suggesting that rheumatoid arthritis and ulcerative colitis may share a similar mechanism of chronic inflammation that does not involve the formation of granulomas.

The macrophage marker profile in the Crohn's colitis sections differed from that seen in the ulcerative colitis and histologically normal samples. In the most severely inflamed sections, the normal colonic mucosal macrophage phenotype was virtually replaced by RFD1 - RFD7+ cells (the classic scavenger macrophages). Many of these cells were 
positive for the peripheral blood monocyte marker UCHM1. Peripheral blood monocytes are negative for the RFD markers but become positive for either RFD1 or RFD7 after seven days in culture. ${ }^{9}$ Therefore the mature tissue macrophage infiltrate in Crohn's colitis probably contains a population of cells that have been recently recruited from the peripheral blood monocyte pool. Another possible source of classical macrophages is the normal RFD1+ RFD7+ colonic macrophage population: these cells may be capable of differentiating into phenotypically distinct antigen presenting cells (RFD1+ RFD7-) or mature tissue macrophages (RFD1- RFD7+). The emerging proportions of these subpopulations would depend on the tissue microenvironment (which may differ in ulcerative colitis and Crohn's colitis), accounting for the differences between the two diseases observed in this study.

Further evidence that macrophage heterogeneity is greater in inflammatory bowel disease than in normal mucosa comes from the immunoperoxidase studies using RFD9. Positive cells were confined to lymphoid aggregates in the normal sections: here the antibody was recognising the so-called germinal centre or tingible body macrophages. By contrast, clusters of free lying RFD9+ cells (epithelioid cells and multinucleate giant cells) were present in Crohn's colitis and, to a lesser extent, in ulcerative colitis - a finding in agreement with Mahida and his colleagues. ${ }^{19}$ The RFD9+ cells were larger and less frequent than RFD7+ cells, being more focally distributed adjacent to disrupted glandular tissue or granulomas. The clear distinction between RFD9+ and RFD7+ cells in Crohn's colitis is also seen in the delayed hypersensitivity granulomas of sarcoidosis. ${ }^{10}$

In conclusion, this study has shown that the majority of normal colonic macrophage like cells recognised by our panel of monoclonal antibodies bear the unusual RFDR1+ RFD1+ RFD7+ UCHM1 - phenotype. Compared with the normal sections, those from patients with inflammatory bowel disease displayed greater heterogeneity of macrophage morphology and phenotypic expression. Further work is being done to examine the macrophage marker profiles in other colonic inflammatory disorders such as infections and ischaemia. The relevance of macrophage heterogeneity to the pathogenesis of the idiopathic inflammatory bowel diseases may become clearer when the results of these studies are available.

We thank Mr A A M Lewis and the other Consultant Surgeons at the Royal Free Hospital for allowing us to study material from their patients. Dr L W Poulter is in receipt of a grant from the Wellcome Trust. We are also indebted to Professor S Pocock for statistical advice and Mrs J Young for typing the manuscript.

\section{References}

1 Ganguly NK, Kingham JGC, Lloyd B, et al. Acid hydrolases in monocytes from patients with inflammatory bowel disease, chronic liver disease and rheumatoid arthritis. Lancet 1978; i: 1073-5.

2 Thyberg T, Graf W, Klingenstrom P. Intestinal fine structure in Crohn's disease. Lysosomal inclusions in epithelial cells and macrophages. Virchows Archiv [A] 1981; 39: 141-52.

3 Meuret G, Bitzi A, Hammer B. Macrophage turnover in Crohn's disease and ulcerative colitis. Gastroenterology 1978; 74: 501-3.

4 Selby WS, Poulter LW, Hobbs S, Jewell DP, Janossy G. Heterogeneity of HLA-DR-positive histiocytes in human intestinal lamina propria: a combined histochemical and immunohistological analysis. J Clin Pathol 1983; 36: 379-84.

5 Wilders MM, Drexhage HA, Kokje M, Verspaget HW, Meuwissen SGM. Veiled cells in chronic idiopathic inflammatory bowel disease. Clin Exp Immunol 1984; 55: $377-87$.

6 Knight SC, Balfour BM, O'Brien J, Buttifant L, Sumershen T, Clarke J. Role of veiled cells in lymphocyte activation. Eur J Immunol 1982; 12: 1057-60.

7 Poulter L, Janossy G. The involvement of dendritic cells in chronic inflammatory disease. Scand J Immunol 1985; 21: 401-7.

8 Turk JL, Narayan RB. The origin, morphology and function of epithelioid cells. Immunobiology 1982; 161: 274-82.

9 Poulter LW, Campbell DA, Munro C, Janossy G. Discrimination of human macrophages and dendritic cells by means of monoclonal antibodies. Scand $J$ Immunol 1986; 24: 351-7.

10 Munro CS, Campbell DA, Collings LA, Poulter LW. Monoclonal antibodies distinguish macrophages and epithelioid cells in sarcoidosis and leprosy. Clin Exp Immunol 1987; 68: 282-7.

11 Janossy G, Bofill M, Poulter LW. Two colour immunofluorescence: analysis of the lymphoid system with monoclonal antibodies. In: Polak J, van Noorden S, eds. Immunocytochemistry: practical applications in pathology and biology. Bristol: J Wright, 1986: 438-55.

12 Hogg N, MacDonald S, Slusarenko M, Beverley PCL. Monoclonal antibodies specific for human monocytes, granulocytes and endothelium. Immunology 1984; 53: 753-67.

13 Mason DY, Abdulaziz Z, Falini B, Stein H. Double immunoenzymatic labelling. In: Polak $J$, van Noorden $\mathrm{S}$, eds. Immunocytochemistry: practical applications in pathology and biology. Bristol: J Wright, 1983: 113-7.

14 Poulter LW, Chilosi M, Seymour GJ, Hobbs S, Janossy G. Immunofluorescence membrane staining and cytochemistry applied in combination for analysing cell interactions in situ. In: Polak J, van Noorden S, eds. Immunocytochemistry: practical applications in pathology and biology. Bristol: J Wright, 1983: 233-48. 
15 McDonald GB, Jewell DP. Class II antigen expression by intestinal epithelial cells in inflammatory diseases of colon. J Clin Pathol 1987; 40: 312-7.

16 Ainsley G, duBois RM, Poulter LW. Relationship between bronchoalveolar lavage, immunocytology and clinical status in sarcoidosis. Sarcoidosis. (In press).

17 Salisbury AK, Duke O, Poulter LW. Macrophage-like cells of the pannus area in rheumatoid arthritic joints.
Scand J Rheumatol 1987; 16: 263-72.

18 Collings LA, Waters MFR, Poulter LW. The lesions of dendritic cells in the cutaneous lesions associated with tuberculoid and lepromatous leprosy. Clin Exp Immunol 1985; 62: 458-67.

19 Mahida YR, Gionchetti P, Vaux D, Patel S, Jewell DP. Macrophage subpopulations in inflammatory bowel disease [Abstract]. Gut 1986; 27: A1245. 